\title{
Women's advancement in journalism: psychological characteristics
}

\author{
Olga V. Smirnova
}

Lomonosov Moscow State University, Moscow, Russia

\begin{abstract}
The feminization of journalism, a process taking place in numerous countries worldwide, has been advancing at a much higher rate in Russia than elsewhere. This trend is based on both global and specifically Russian factors. The gradual migration of journalism from being a typically male profession to being a predominantly female one brings about a number of inner transformations and creates a certain inner psychological climate. To fully understand these changes, researchers should set new goals for their studies based on an analysis of gender transformations in journalism and on investigations of possible problems and conflicts entailed in the process.
\end{abstract}

Keywords: journalism, feminization of journalism, women's promotion strategies, psychological characteristics

One of the trends that can be observed today is the steadily increasing female presence in professional spheres and management positions traditionally regarded as "male." The range of opportunities for education and professional training is expanding, and today many women are able to obtain qualifications that allow them to apply for new positions in new areas. "The glass ceiling," which reflects both gender inequality in the social and economic spheres and rigid stereotypes of men's and women's social roles, is gradually being destroyed. Women are stepping outside traditional occupations with limited responsibilities, low salaries, and few chances for promotion.

These processes are intense in the sphere of journalism. For instance, in Western Europe and North America, critical growth in the numbers of women in journalism began in the late 1970s and early 1980s, following the launch of women's open struggle for their rights. Gender equality came to be associated with the development of democracy, and protest movements had an effect on media content.

The atmosphere in editors' offices had been changing since the beginning of corporate debates about "sexist jargon," male workers' abuse of alcohol, sexual harassment, lower salaries for women, and other signs of gender inequality (DjerfPierre, 2007). This period resulted in the strengthening of the status of female jour- 
nalists, a status that no longer had marginal connotations. Women were granted access to traditionally male spheres and positions in journalism.

However, for a large part of the 20th century, the presence of female-oriented material in Soviet periodicals that were not aimed solely at women was still an exception. As a rule, in the sphere of journalism, women took positions that were not prestigious enough for men and that mainly involved the technical aspects of data preparation: stenographers, typists, proofreaders. With the spread of mass television, the need for female presenters arose.

Although the feminization of journalism has been a steady trend both in the West and in Russia, in Russia it was influenced by different factors, despite the seeming similarities of the process in different countries. The feminization of journalism in this country was hardly affected by such phenomena as the struggle for gender equality.

Because Soviet women initially enjoyed equal rights with men, they should have gradually been entering the journalistic and media field. However, through all of the Soviet period, the profession of journalist remained predominantly male, and this stereotype held firmly in public consciousness. On the whole, the feminization of journalism was developing at a much slower rate in Soviet Russia than in most European and North American countries.

The intensification of this process in Russia began in the early 1990s; it was brought about by inner social and political transformations rather than as a vindication of women's rights. The commercialization of the previous state media made this sector economically unstable, which was especially obvious at the early stages of perestroika, when journalists' salaries went down and the prestige of the profession was damaged. These factors as well as others forced many men to abandon the profession or to remain in managerial positions only. The vacant media spots were soon taken by women, who were less demanding in regard to working and payment conditions.

Therefore, journalism turned into a "female" professional sphere in Russia as the result of social and political changes in the country rather than because of the promotion of gender equality as in the West.

In the 2000s the media sector in Russia was characterized by a much higher degree of stability than in the 1990s. According to the Gender Pay Gap in Journalism Report (2012), Russia had the highest pay level for journalists of any of the former USSR states; the average monthly salary equaled 929 USD or 20,932 RUB (compared with 654 USD in Ukraine).

However, the influx of women into the media has not stopped, this time in accordance with global rather than specifically Russian trends; an example is the increasing differentiation in the media system, which has had a major effect on media content worldwide. The borders between the public and the personal have been fading; personification trends and the shift to individual feelings and experience have come to life; and the share of information having to do with the needs and interests of the audience as such has increased. The new journalism has actually acquired the features of the phenomenon that in the 1990s used to be defined as "female journalism." To a great extent, the female journalist has met the needs of today's audience. 
However, despite significant quantitative changes, social and psychological attitudes that reflect the gender stereotypes typical of the Soviet era still hold in the professional consciousness.

In spite of the proclaimed equality, gender segregation in the USSR was quite noticeable. Besides the gender differences in working hours, men and women performed different kinds of tasks; the so-called female spheres and positions were considered less valuable from the perspective of qualification requirements and rewards.

Professional segregation can be seen in the fact that there were female managers only in certain sectors in Soviet times. Thus, the new processes that emerged in journalism in the 1990s left researchers somewhat confused and required reframing and new approaches. In this context, the gender aspects of journalism became one of the key objects of research.

World academic science has long recognized gender research as a cross-disciplinary practice that employs the theories of social gender in the analysis of social phenomena. Academic gender research dates back to the 1960s, although it was in the 1970s that liberal science developed an approach that demonstrated the urgency of studying gender inequality. In the 1970s, foreign researchers began to actively analyze the social equality of women as expressed by the media, which played an important part in drawing attention to this topic. In particular, the increasing number of female journalists and their professional achievements provided a broader view on the subject of gender and the media (Byerly \& Ross, 2006). At the early stages of this research, the focus was on filling the gaps in the knowledge of women, gaps that had been brought about by the traditional approach. The key task was to study women's experience: researchers stressed the status and role of women in journalism and the mere fact of their presence in the profession. In the 1980s and 1990s, at the stage when the concept of gender was no longer viewed as a purely "female" issue, a new system of relations allowed the segmentation of society based on the criterion of gender. The gender research of the media expanded and developed more profound reasoning. An approach to gender and media research problems was developed as well: researchers gradually turned from providing the background of female journalists to analyzing the representation of women in the media, the role of gender issues in the information agenda, sexist manifestations in the media and advertising, and other topics. The increasing tempo of the feminization of journalism caused scientists to focus on those processes. On the one hand, the new trends promoted gender equality, but, on the other hand, they brought about psychological problems and contradictions that arose in the context of increasing competition between male and female media employees.

Among the researchers looking into these aspects were C. M. Byerly, K. Ross, M. de Bruin, L. Von Zoonen, M. Djerf-Pierre, M. Melin-Higgins, S. Torkkola, and L. Ruoho (Byerly \& Ross, 2006; de Bruin \& Ross, 2004; Melin-Higgins, 2004; Von Zoonen, 1998).

Some of the key directions for studying the gender aspects in media are as follows:

- Analyzing gender balance, including the positions and payment levels of men and women in various sectors of journalism 
- Studying the forms of professional competition between men and women; the differences in requirements for men and women concerning their professional skills, education, age, and other types of "capital" needed to work in the media sphere; as well as the strategies that women choose to get promoted

- Studying the influence of the growing presence of women in journalism on the culture and the differences in men's and women's understanding of the key professional values

Undoubtedly, the analysis of gender balance is an important line of research, as are the professional positions and payment levels for men and women in journalism. In public opinion and, moreover, from the perspective of many journalists, journalism still remains a typically male sphere, and the presence of "a few" women in the profession is viewed as a "system error" and nothing but a temporary trend. The stance voiced by V. Bakshin, the head of the Vladivostok State Television and Radio Broadcasting Company, a branch of the All-Russian State Television and Radio Broadcasting Company, and the director of the Mass Communications Institute, is quite typical. When asked "Is journalism a male or a female profession today?" he replied:

In its essence it's male. But in reality, it's female. For example, from my colleagues in the United States, I have learned that about two thirds of American journalists are women. And in Russia their share makes up 90\%! This has an impact on the profession as a whole: it is a well-known fact that men and women have a different mentality, that men are more adept at analysis. Besides, journalism is quite a risky and dynamic job, and it is rather difficult to combine it with family life. In addition to that, our profession, especially in the spheres of television and radio, is quite cruel to ladies reaching a certain age. No matter how qualified a lady-journalist is, she has to realize that at a certain point she will have to leave her microphone and move on to the editor's chair. Many women turn to careers in mass-media management as well. I can say that the Far East market of journalist vacancies is more open to men. Not just talented, but also hardworking (Shipilova, 2011).

Thus we can see that the quantity of women in journalism does not bring about a favorable assessment of the quality of their work: most often, a female journalist's work is assessed on the basis of widespread gender myths.

Therefore, despite the importance of analyzing the numerical figures of gender inequality in the sphere of journalism, one of the most interesting trends is research on various aspects of career equality and on the characteristics of women's promotion strategies.

Leadership experts single out organizational, social, and individual obstacles on a woman's way to promotion (Indvik, 2004, pp. 273-282), among which they name the prejudice that a woman faces from staff, her unwillingness to take part in "under-the-table" games, and the difficulties of combining professional and family life.

Gender stratification leads to differences not only in the realization of various opportunities but also in the strategies for obtaining them (Zdravomyslova \& Tyomkina, 2007, 29). In the context of the different characteristics of males and fe- 
males, the mechanisms and values to which women resort to compensate for their gender are quite illustrative. "Gender display," which reflects differences in men's and women's expertise, becomes especially obvious in the sphere of journalism.

All journalists irrespective of gender are subject to gender stereotypes that inevitably have an impact on the product they create as well as on their own position and self-realization in their profession. Gender identification can be transformed in a career depending on the environment. As Zinchenko (2011) remarks, "As a matter of fact, a human being discovers the world around through social representations and interprets social reality accordingly" (p. 309).

An analysis of professional journalism publications was conducted, as well as a study of Russian Internet resources devoted to research on journalists' activities. The analysis of positions connected with the professional strategies employed by female journalists in Russia reveals two dominant strategies.

The first strategy is based on the desire to highlight feminine nature, including typical women's features and psychological characteristics. Female journalists who choose this strategy accept the fact that the presence of women in the profession is a kind of "deviation" and adjust to the existing order in their own ways. This strategy, an emphatically feminine approach to journalism, definitely prevails today. Quite often, consciously or subconsciously, female journalists resort to stereotypical characteristics, primarily psychological ones. Thus they build up their own psychological image to match popular gender concepts and traditional gender stereotypes. Consequently, by thinking that they have to adjust to the terms set by society, they activate the power and manipulation tools that allow them to exert a certain subtle influence.

The second strategy is based on the urge to bring one's professional skills and achievements into focus. The intention is to position oneself by abandoning typical gender characteristics. Female journalists employing this approach deliberately avoid traditional "women's" subjects and aim to prove that they can write on such topics as the economy or politics just as well as men do. They belong to the pool of female journalists who create true competition among the editorial staff, including their male colleagues. In this situation, women have to make a much greater effort than men do in order to withstand the competition. They realize that they cannot afford errors or weaknesses and have to try much harder than men do to combine private life and career, sometimes making a fully conscious choice in favor of their careers.

Undoubtedly the obstacles that women choosing the second strategy face are more complicated than those facing women who choose the first strategy. Most often these obstacles have a psychological nature and are not always obvious even to the women themselves; however, many of them admit that such problems do exist. These women regard the very notion of female journalism as derogatory and believe it dissociates their work from "true" journalism.

As was mentioned above, persuading society that journalism is a sphere for both genders takes a much greater effort from women than from men. According to Bourdieu's concept (1998), participants in any social sphere employ different strategies to win certain positions and influence. The stakes in this competition include success, prestige, status, and, finally, the authority to decide who is to be acknowledged as a member of a profession and what the professional benefits 
and values will be. A struggle for resources to reach leading positions and for the "capital" that is valued in the sphere becomes inevitable. From Bourdieu's perspective, the phenomenon of capital reaches beyond the purely economic. Anything that is appreciated and sought-after can be regarded as capital. Among the values in question we can single out the symbolic (such as status, prestige, legitimacy), the cultural (education, titles, distinction), and the social (family, personal connections). Gender or gender identity is also a form of symbolic capital that has a different value in different spheres (de Bruin \& Ross, 2004; Moi, 2001). Wherever the female gender is viewed as having a negative symbolic value, a woman has to make up for it with other forms of capital: professional, cultural, economic, or social.

The problem of gender inequality certainly exists in the television sphere, and nobody even tries to conceal this. It is a well-known fact that it is easier for a man than for a woman to find a job in television. It is believed that television is lacking in men, with the federal (as well as the regional) channels constantly fighting for fresh "male faces." Ladies get offended, and I can understand them. Even with a tremendous talent, it is quite difficult to make a career in television (Zaytsev, 2008).

As for the opinion of female journalists, by focusing on various psychological characteristics, some of them view their gender as a positive value, some as a negative value.

Journalism, which we have chosen, is actually a hard job, second only to that of a miner in death rates. However, in my opinion, it is only thanks to women that this "male" profession is surviving today. Unlike men, they are more hardworking, persistent, and ... less ambitious (Vladimirova, 2011).

I do believe that even a most successful woman can be taken aback by a stupid question at a class reunion, like a question about why she still isn't married. But generally, women are more hardworking, they rarely complain. They are also more flexible, which is both their advantage and their disadvantage. It is easier for them to adjust to the current environment, easier to change their opinion, especially under the influence of men (Kalinina, 2012).

Russian female journalists often assess their own drawbacks and merits with some irony and yet with a certain self-confidence: "Women in journalism have great power.... When dealing with female journalists, men get nicer and smarter, trying to make an impression, and women take part in a contest, competing to prove who's prettier and better (Varkan, 2009).

Meanwhile, women's professional "flexibility" can sometimes lead to contradicting existing rules and norms, and not only in professional aspects:

Only a woman is able to deceive the security guards of the first president of Russia, spy on him at the VIP box in the Bolshoi Theatre during the Triumph Awards ceremony, and then run away from the same security guards, hiding in the cafeteria, and, at the same time, making a live report on what is actually going on. Only a woman. 'Cause meanwhile, her male colleagues demonstrate their principles and compliance with the rules, which means they are able to do anything and know everything, and, first of all, know 
their place. That is why they keep sitting locked in their boxes at the very same theatre under the control of the very same security guards. And with this approach to business, very soon, the only thing left for women to do will be presenting weather forecasts. Live weather forecasts, to be precise. (Varkan, 2009)

The analysis of publications in which female journalists examine the characteristics of their profession helped define the following "positive" gender values as those that give them a certain advantage over their male colleagues:

- Gentleness (often in the context of outer gentleness and inner toughness)

- Lack of aggression

- Flexibility

- High efficiency standards

- The ability to override rules/conventions/principles

- The ability to attract the interlocutor's attention

- The ability to adjust to the existing situation

- Readiness to change a position

- Lack of ambition

- The ability to multitask

- The certainty that journalism is indeed "a profession for women"

These qualities can actually be assessed as negative when considered from a different (or male) perspective. For example, flexibility and the ability to disregard rules can be seen as deception; the ability to attract attention, as flirting. Bourdieu (2001) points out this peculiarity in his work Masculine Domination, mentioning the negative characteristics that the "dominant opinion" ascribes to women-for example, cunning or intuition.

Although journalism has its peculiarities as a creative profession, the notion of a career in journalism can reach beyond merely climbing up the professional hierarchy. The publicity of the field brings about the ambition to gain popularity and fame, the absolute values of the profession often prevailing over career, status, and even salary level. In this connection, unusual career modifications that are also marked by their gender characteristics come to life.

Gender and age still largely influence the differences in career types in journalism. These differences demonstrate not only individual choice but also cultural conditions and the obligations stated in the contract that define the development opportunities of an employee. Gender strategies exert an increasing influence on the professional culture as a whole, which has been noted by many researchers (Djerf-Pierre, 2007). For example, they highlight the existence of "male" and "female" approaches to news coverage: men's ability to be objective and to distance themselves from the reader and women's tendency to be subjective and intimate and to raise empathy. In addition, striving for professionalism as a key goal is defined as a male feature, while the prevailing urge to meet readers' needs and interests is more typical of females (Djerf-Pierre, 2007, 97).

In addition, researchers mention as characteristic of female journalists the trends to override genre limits and to experiment with form and content instead of following set rules, as well as the ability to easily combine or to differentiate job 
and private life (Carter, Branston, Allen, 1998; de Bruin \& Ross, 2004; Djerf-Pierre, 2007; Robinson, 2005; Von Zoonen, 1998).

On the one hand, the feminization of journalism in Russia is in line with global trends, but, on the other hand, it reaches excessive levels. No matter which side dominates, the consequences of gender misbalance will still be dramatic. In regard to gender, journalism should be a balanced profession because the preponderance of either party can cause significant damage. At the same time, gender stereotypes that portray the profession as typically male remain strong in Russian journalism; such stereotyping creates quite a negative psychological climate. It should also be mentioned that female journalists are influenced by gender stereotypes no less than their male counterparts are.

In most cases, female journalists who do realize how much gender stereotypes as well as the job as a whole might affect them give up their media career ambitions. Those of them who strive to overcome gender prejudice usually avoid straightforward strategies that depict their gender as an absolute value. Some female journalists tend to manipulate their gender identity by accepting their subordinate positions in the profession while at the same time employing overly "flexible" or "female" ways to achieve their goals. Others demonstrate their readiness to figuratively give up their gender identity and typically female personal traits while trying to acquire and demonstrate certain "masculine qualities." Both ways undoubtedly lead to stress, psychological tension, and the choice of manipulative gender strategies. Certainly, the elaboration of efficient strategies that will help eliminate gender misbalance in the profession and cope with its negative economic and psychological consequences is the key task of research in this area.

\section{References}

Bourdieu, P. (1998). On television. New York: New Press.

Bourdieu, P. (2001). Masculine domination. Palo Alto, CA: Stanford University Press.

Byerly, C. M., Ross, K. (2006). Women and media. A critical introduction. Cambridge, MA: Blackwell. doi: 10.1002/9780470774908

Carter, C., Branston, G., Allen, S. (1998). News, gender and power. London: Routledge.

De Bruin, M., Ross, K. (Eds.). (2004). Gender and newsroom cultures: Identities at work. New York: Hampton Press.

Djerf-Pierre, M. (2007). The gender of journalism: The structure and logic of the field in the twentieth century. Nordicom Review, 28, 81-104.

Gender Pay Gap in Journalism Report. Wage Indicator Global Report 2012 (2012). Retrieved from: http://www.if.org/assets/docs/196/153/728fdc4-8ae1999.pdf

Indvik, J. (2004) Women and Leadership. In Northouse, P.G. (Ed.), Leadership: Theory and practice. California: Sage Publications

Kalinina, N. (2012). Natalya Bilan: "Esli otnosit'sya k muzhchinamkak k det'am, problem budet men'she" [Natalya Bilan: "If you treat men as children, you have fewer problems"]. Forbes Woman. Retrieved from http://www.forbes.ru/forbes-woman/zhenshchiny-vbiznese/84803-esli-k-muzhchinam-otnositsya-kak-k-detyam-problem-budet-gor

Melin-Higgins, M. (2004). Coping with journalism: Gendered newsroom culture in Britain. In M. de Bruin, K. Ross (Eds.), Gender and newsroom cultures: Identities at work (pp. 197-222). New York: Hampton Press. 
Moi, T. (2001). What is a woman? And other essays. New York: Oxford University Press.

Robinson, G. (2005). Gender, journalism and equity: Canadian, US and European perspective. New York: Hampton Press.

Varkan, E. (2009). Zhenshina v zhurnalistike kak zhanr [The woman in journalism as a genre]. Feminisn'ts. Retrieved from: http://www.feminisnts.ru/285-zhenshina-v-zhurnalistike-kakzhanr.html

Shipilova, O. (2011) Zhurnalistike nuzhny muzhchiny [Journalism needs men] Konkurent.Ru. Retrieved from http://www.konkurent.ru/list.php?id=2006

Vladimirova, M. (2011). Zhenshiny v zhurnalistike [Women in journalism]. Retrieved from http://professionali.ru/Soobschestva/zhurnal_zhurnalist/zhenschiny_v_zhurnalistike

Von Zoonen, L. (1998). One of the girls? The changing gender of journalism. In C. Carter, G. Branston, S. Allen (Eds.), News, gender and power, 33-46. London: Routledge.

Zaytsev, I. (2008). Gendernyi perekos v obshestve: Vi ego zamechaete? [Gender inequality in society: Do you mention it?]. Retrieved from http://www.dela.ru/weekly/19561/

Zdravomyslova, E., \& Tyomkina, A. (2007). Sotsial'noe konstruirovanye gendera kak metodologia feministskogo issledovany'a [Social construction of gender as a method of feminist research]. In Zdravomyslova, E., \& Tyomkina, A. (Eds.), Rossyiskyi gendernyi poryadok. Sotsiologitcheskyi podkhod [Russian gender order. A sociological approach] St. Petersburg: EUSP Press.

Zinchenko, Yu. P. (2011). Security psychology as social systemic phenomenon. Psychology in Russia: State of the Art, 4, 307-315. doi: 10.11621/pir.2011.0019 